fallecimiento el 14 de julio de 1343 o 1344. Tanto durante su vida como después de su muerte, sus hagiógrafos recogen muchos milagros obrados gracias a su intercesión ${ }^{17}$.

Por lo que se refiere a la iconografía de Santa Toscana, Fuentes y Ponte al describir el retablo de la Virgen del Coro, en el interior del coro conventual cita una imagen de esta santa: "Sobre el cornisamiento general del primer cuerpo, se alzan a los lados estremos, dos romanatos dobles, o partidos en cada uno, y detrás de los mismos dos templetes con frontones triangulares y estatuas estando en el izquierdo la de Santa Toscana, religiosa Sanjuanista y en el derecho Santa Cecilia..." ${ }^{\prime 18}$. Efectivamente, en distintas fotografías de principios del siglo $\mathrm{XX}^{19}$ que reproducen el muro de separación del coro de las religiosas con la iglesia, con una puerta central -encima de la cual se encontraba el relicario- y dos retablos laterales, puede verse en el retablo de la izquierda, dedicado a la Virgen del Coro, en el segundo cuerpo -como describe Fuentes y Ponte-, y en el lado izquierdo, la imagen de Santa Toscana, con el hábito sanjuanista, cuya cruz se advierte en el pecho, con velo blanco sobre la toca (fig. 4).

De otras dos imágenes de estas santas da también noticias Fuentes y Ponte: "Destácanse asimismo de las paredes sobre las dos sillerías góticas de los lados unas estatuas modernas entre las que están Santa Waldesca, Santa Toscana, San Joaquín, San Cristobal y San Antonio"20.

En las mismas fotografías que antes mencionábamos pueden advertirse, en los laterales, junto al muro de cerramiento del coro y sobre ménsulas colocadas en la pared, dos imágenes de monjas sanjuanistas que, indudablemente, se trata de las que mencionaba Fuentes y Ponte. En ambos casos visten el hábito de la orden de San Juan de Jerusalén y parece tratarse de obras del siglo XVIII (vid. fig. 4).

Wifredo Rincón-García Instituto de Historia, CCHS, CSIC

\title{
UNA APORTACIÓN A LA EBANISTERÍA GRANADINA EN LA SEGUNDA MITAD DEL SIGLO XIX*
}

Una puerta de marquetería del museo Franz Mayer de México ha sido el hilo conductor para conocer la existencia de talleres granadinos de reproducciones e interpretaciones de mobiliario antiguo así como su exportación y éxito en el mercado internacional.

Palabras clave: Taracea; Juan Facundo Riaño; Rafael Contreras; Mueble español; siglo XVIII.

A marquetry door in the Franz Mayer Museum (Mexico) has served as the key for discovering the existence of $19^{\text {th }}$-century Granada furniture workshops where reproductions and interpretations of ancient pieces were made. They were widely disseminated and enjoyed great success on the international market.

Key words: Marquetry; Juan Facundo Riaño; Rafael Contreras; $18^{\text {th }}$ century; Spanish furniture.

La tradición de la taracea granadina de origen nazarí y su pujanza en la primera mitad del siglo XVI persistió en el buen hacer de los carpinteros granadinos a lo largo de los años, abierta

17 Sobre la biografía de Santa Toscana ver: GoRdinI, Gian Domenico: “Toscana, santa”, Bibliotheca Sanctorum, Istituto Giovanni XXIII della Pontificia Università Lateranense, t. XII, Roma, 1969, p. 719.

18 Fuentes y PONTE, 1890, vol. II, p. 61.

19 Una de ellas figura en el libro de PANO, 2004, p. 133 y la otra, en la Unidad de apoyo y tratamiento archivístico del Centro de Ciencias Humanas y Sociales del CSIC, que es la que hemos utilizado para ilustrar este artículo.

${ }^{20}$ Fuentes y Ponte, 1890, vol. II, p. 65.

* Este artículo se ha elaborado en el marco del proyecto de investigación «Los pavimentos marmóreos del Palacio Real de Madrid» (HUM 2006/6665). 
a las influencias externas, que en el caso de los muebles fueron más de índole flamenca, que italiana y llegadas prácticamente siempre a través de Sevilla.

Entre los documentos de carpinteros y ebanistas que trabajan en Granada en el siglo XVII figuraron varios flamencos, llegados efectivamente desde Sevilla. Muy al principio del siglo XVII, en 1614 un tal Cebrian de Artus, "maestro de hacer sillas flamencas, de nación flamenca, vecino de Sevilla y estante en Granada" vende a Juan Pascual, también flamenco asentado en Granada, las herramientas para hacer sillas de Flandes ${ }^{1}$. Otros flamencos como José Nobilis, "ebanista que labra escritorios de ébano" en 1638 aparecen citados por don Manuel Gómez Moreno en unas interesantes páginas sobre la carpintería granadina, que han sido editadas hace pocos años ${ }^{2}$. La actividad de este ebanista, por ahora desconocido, se ve apoyada años más tarde por otras noticias documentales. El 12 de abril de 1677, Ventura de Cuenca, maestro de ebanistería de Granada, vecino de las Angustias, en la calle de San Miguel, se compromete con D. Antonio de Teruel Messía del Castillo, a hacerle "dos contadores de vara y media de largo y la mitad de alto de madera de nogal, carey, marfil, palosanto, etc., debiendo fijarse su importe final mediante tasación" . Gómez Moreno continuaba "Hacia mediados del XVII comenzaron a revestirse los delicados y vistosos muebles con enchapaduras de maderas finas, marfil, carey, filamentos de plata y sobrepuestos de bronce dorado. Las papeleras de entonces tienen adornos y figurillas grabadas sobre placas de marfil".

El uso de la concha o carey fue constante en Granada, utilizándose sobre todo para las cruces procesionales, como la del Cristo de la Misericordia de José de Mora ${ }^{4}$, la del Nazareno de la Cofradía del Vía Crucis, atribuida también a Mora o la del Calvario de Diego de Aranda en la iglesia del Sagrario ${ }^{5}$ y en las urnas o escaparates asimismo para guarnecer las imágenes, advertida también por Gómez Moreno "abundan las urnas y entre ellas reviste mayor importancia la que hace de Santo Sepulcro en la iglesia de santa Ana costeada en 1675 por Manuel de Valdés". Precisamente ésta es muy cercana a las conservadas en Écija o Logroño, la primera labor sevillana documentada como obra de Cristóbal de Yepes de $1711^{6}$.

Este tipo de trabajo siguió desarrollándose con mayor pujanza si cabe en el siglo XVIII, destacando sobre todo la conocida obra de Fray Manuel Vázquez para la Cartuja granadina. Para la Sacristía labró, a lo largo de diecisiete años (1730-47), todas sus puertas, cajoneras y alacenas, enchapadas de caoba, ébano, palosanto, marfil, concha y plata (fig. 1) y un poco más tarde en 1750 el cancel de la iglesia que separa el coro de monjes del de frailes, con puertas de cristales en la parte alta y revestido de marquetería el resto.

Tres modelos diferentes aunque muy similares conforman las puertas realizadas por fray Manuel Vázquez: la puerta de entrada, la de legos y las dos de los armarios (fig. 3). Siendo similar el tipo de labor a base de marquetería de caoba, ébano, granadillo, carey y huso o marfil y aplicaciones de plata, difieren en su composición las dos primeras a base de cuadrados, rectángulos y rombos, subrayados por el fuerte contraste de una moldura bicolor, mientras que para

1 AH. P. Granada. Prot G-479, fol. 490r, en Gila Medina, L. Maestros de carpintería en las Granada Moderna según los escribanos de la ciudad. Monvmenta Protocollaria 2. Granada 2008, p. 91.

${ }^{2}$ Gómez-Moreno Martínez, Manuel: La Carpintería en Granada. Documentos y estudios de arte granadino 2. Instituto G. Moreno de la Fundación Rodríguez Acosta. Granada 2001, pp. 101-104. Manuscrito fechado en 1898 que fue presentado al concurso anual de la Sociedad Económica de Amigos del País. Prologado por M. ${ }^{a}$ del Carmen López Pertiñez se afirma que estuvo prestado a Bermúdez Pareja y posiblemente fue consultado también por Torres Balbás.

3 AHPG, Prot. G-878, fols. 556r/557r. Cfr. Gila MedinA, op. cit., p. 165.

${ }^{4}$ Gómez Espina, Teresa, "Cruz de taracea del Cristo de la Misericordia. Informe Histórico-artístico" en Santísimo Cristo de la Misericordia de José de Mora. Granada 1995, pp. 19-22.

5 Martínez Medina, Francisco Javier, Cultura religiosa en la Granada renacentista y barroca: estudio iconológico. Granada 1989, p. 428.

6 Teatro de Grandezas. Junta de Andalucía 2007, p. 292. 


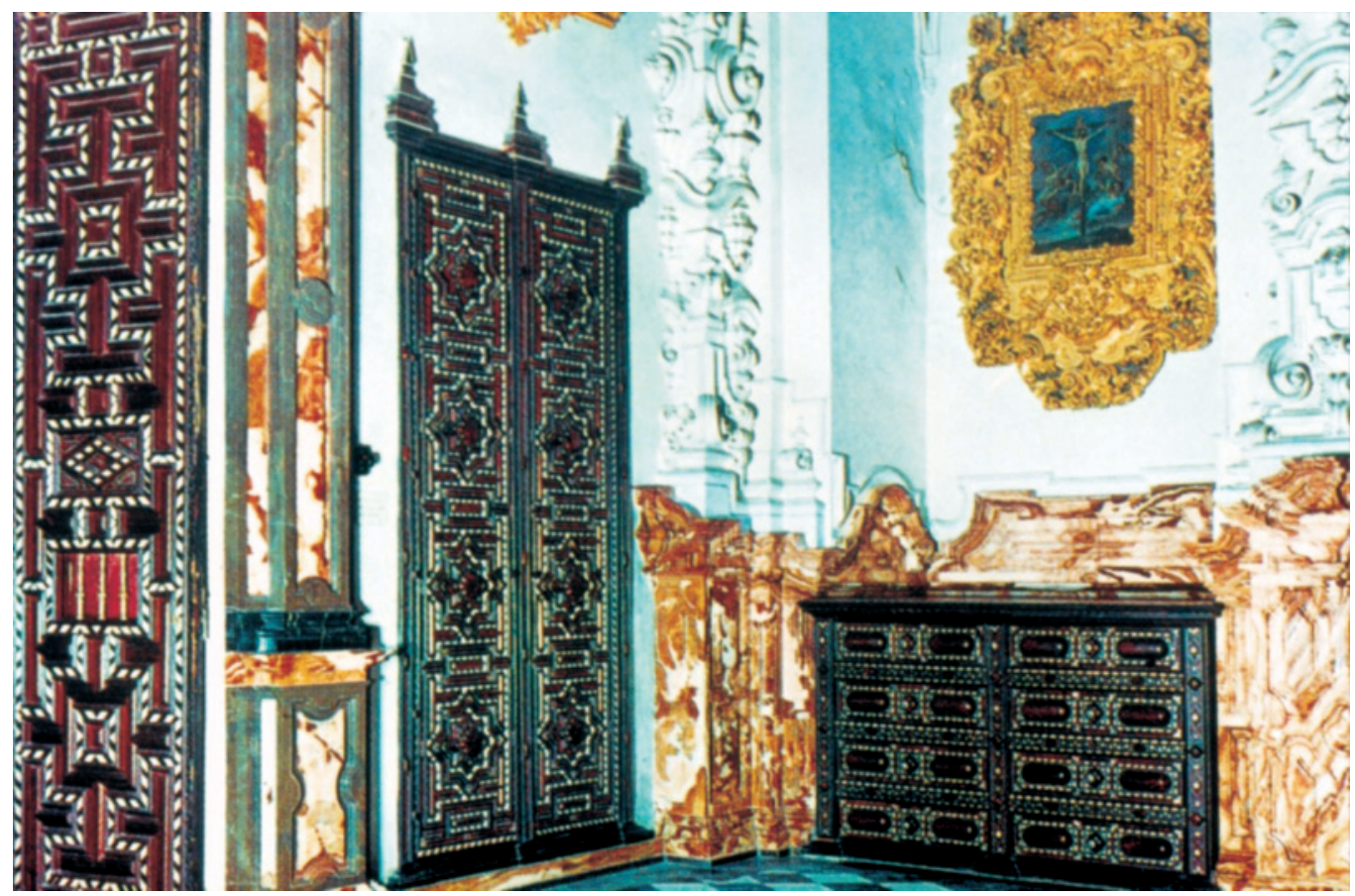

Fig. 1. Granada. Sacristía de la Cartuja. Mobiliario 1730-47.

los armarios se prefirió resaltar la importancia de la estrella de ocho puntas de raigambre nazarí, pero sin girar, es decir, sin cruzarse formando un lazo, sino desarrollándola de forma concéntrica, subrayada por las molduras rizadas y los segmentos de hueso. Si las puertas de los armarios tienen poco relieve, las otras dos tienen profusión de cabujones en carey con los que se realizaron a juego las cajoneras, cuyos frentes de las gavetas ostentan mayor volumen (fig. 2).

A éstas se le puede encontrar una fuente de inspiración precisa en los escritorios "de aparato" flamencos del siglo XVII. El sistema de organizar los frentes de las gavetas a base de cabujones chapeados de carey es una de las principales aportaciones del mobiliario flamenco a lo europeo, influyendo tanto en el mobiliario inglés ${ }^{7}$ del último tercio del siglo XVII como en el italiano y en el español.

Gallego Burín las puso en relación con las taraceas de mármoles de los frontales de los altares, cuya entrada por el contrario creemos que se debió más al conducto italiano que al flamenco, pero ya afirmaba que "era tanta su perfección y tan original que forjó los cimientos de una escuela que ha llegado hasta nuestros días"

Gómez Moreno en la obra citada aseveraba esta actualidad (refiriéndose a la segunda mitad del siglo XIX): "de muy pocos años a esta parte la ebanistería logra de nueva impulso en esta localidad avivada por el comercio y las falsificaciones. Se fabrican muebles de toda especie y de todos los estilos ya árabes imitando los atauriques y mocárabes de la arquitectura y dándoles apariencia e edificios en miniatura, grave anomalía y defecto capitalísimo, que arguye completa ignorancia y falta de sentido artístico de sus autores. Ya son a estilo del Renacimiento que pecan

\footnotetext{
7 Jervis, Simon, A tortoishell cabinet and its precursors. Victoria \& Albert 1969, fig. 1.

8 Gallego y Burín, Antonio. El Barroco Granadino. Granada 1956, nota 163.
} 


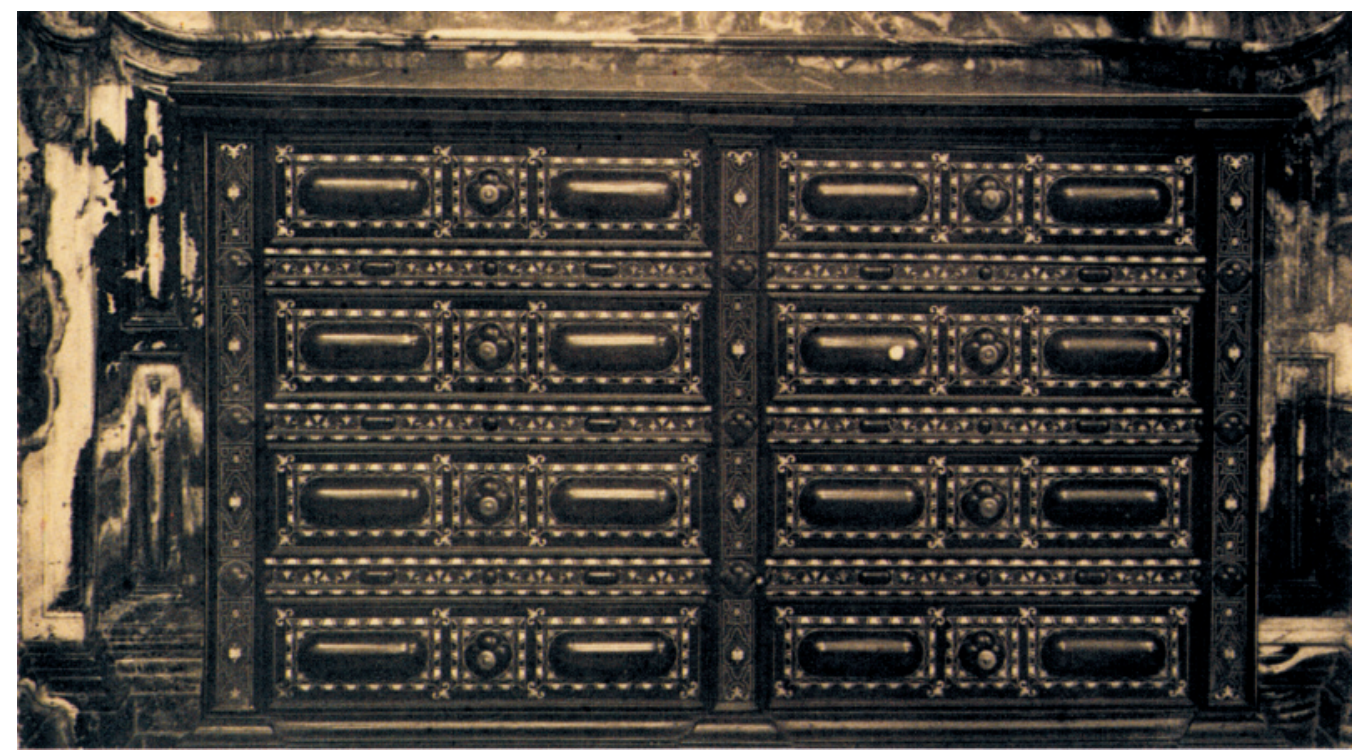

Fig. 2. Cajonería. (Foto G. Moreno).

asimismo por su impericia en el diseño, rutinarismo en la invención y sequedad de factura, ya son imitaciones más correctas y aceptables de taracea mudéjar y de enchapaduras, las más de estilo italo-flamenco, otras copiando los modelos de la Cartuja, y nada tiene que envidiar a lo antiguo salvo la distancia que media del arte que se siente a la industria servil y mecánica. Además entraña gérmenes de estacionamiento y depreciación"9.

Esta apreciación de Gómez Moreno que evidencia la situación circundante granadina, se ve confirmada documentalmente con nombres y apellidos, en la correspondencia que Juan Facundo Riaño mantuvo con el londinense museo de South Kensington. Riaño como experto para la adquisición de arte español, desde los años sesenta, una vez vuelto a instalarse en Madrid, notificaba a Henry Cole los objetos útiles tanto para el museo como para la School of Design, ya que como afirma Marjorie Trusted, Riaño estaba más de acuerdo en adquirir productos españoles que representaran a la industria española que en las grandes obras de arte como prefería Robinson $^{10}$. Fiel a esta intención educacional mostrada por ambos, aunque el museo londinense ya disponía de veintiséis modelos pequeños de la Alhambra, otros muchos producidos por el taller de Contreras, el director de restauración de la Alhambra, se enviaron en 1890 y se dispusieron en las British Galleries como ejemplo de la influencia de las formas árabes en el arte británico del siglo XIX ${ }^{11}$.

En su carta del 31 de julio de 1872 desde Granada afirmaba "Se estan haciendo en Granada algunos interesantes ejemplos de mobiliario artístico por encargo de Mr. Frederic Power que tienen un carácter local relevante y podían ir para el museo, ... otras cosas de mobiliario artístico las hace un carpintero de Granada Eduardo Martin... que ha imitado y copiado con exactitud admirable las magníficas puertas de los armarios de la cartuja de Gra-

\footnotetext{
9 Gómez Moreno, op. cit., p. 104.

10 TRUSTED, Marjorie, "In all cases of difference adopt Signor Riaño's view: Collecting Spanish decorative arts at South Kensington in the late nineteenth century", Journal of the History of Collections, núm. 18, 2006, pp. 225-236.

11 TRusted, M., op. cit., nota 30.
} 
nada, obra de fin del siglo XVII, completamente cubierta con ébano, concha taraceada con plata, marfil madreperla en un admirable diseño de líneas de tracería geométrica. Este carpintero ha hecho los armarios y una cómoda. La delicadeza del acabado y la perfección de la labor son admirables y dignas de toda alabanza. Si le interesa al departamento tener un espécimen de alguna de estas cosas puedo informarle de las diferentes medidas y precios" 12 .

La respuesta fue sin duda afirmativa pues dos meses después, el 30 de septiembre de 1872 , escribe que ha hecho las indagaciones con el citado Eduardo Martín, que ya ha enviado a Londres los dos armarios y la cajonera a casa de Mr. Frederic Power, al 59 de Cronwell Rd. y repite la explicación de que se trata de una reproducción de la sacristía de la Cartuja realizada por fray Manuel Vázquez en 1697-1775 (sic), indicando que de ellas ya "hacía mención la Guide to Spain and Portugal de Henry O'Shea en la página 198 "13.

Tras estas notas Riaño continua las alabanzas y le hace ver que el precio fue de 250 guineas por cada uno sin incluir cerraduras ni las aplicaciones metálicas, pero que el propio ebanista afirmaba que una vez superadas las principales dificultades iniciales, podría hacerlas por

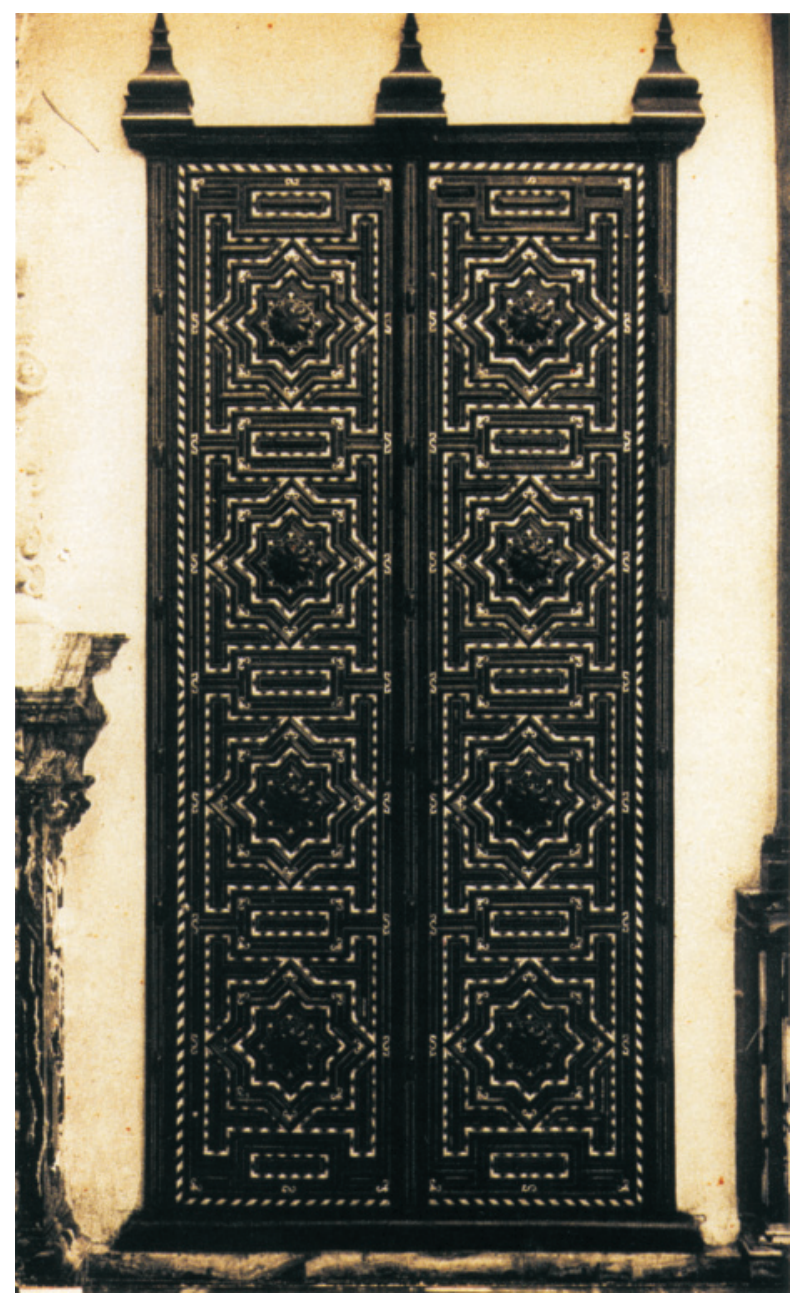

Fig. 3. Puerta de armario. (Foto G. Moreno). 220 y que estaba realizando otra cómoda para Mr. Power, ofreciendo enviarla al museo cuando la terminase para la Exposición. En nota manuscrita, Eduardo Martín de la calle de los Tintes 23, Granada, fija el precio de sus muebles en 25.000 reales cada uno, opinando que puede bajar a 12.000 reales $^{14}$.

Una de esos muebles realizados por Eduardo Martín es, sin duda, la puerta conservada en el Museo Franz Mayer de México (fig. 4), entre cuya documentación no hay constancia, que sepa-

12 Victoria \& Albert Museum Archives, J.F.Riano. Reports of professional Referee 1870-1873, Part I. MA/ R741- Part II. Reports of professional Referee 1873 /R741. Agradezco a Mr. James Yorke, conservador del Museo el conocimiento de esta documentación.

13 Consultadas las diferentes ediciones hasta 1901, de la que probablemente fue la guía más popular en Inglaterra durante la segunda mitad del siglo XIX, un párrafo en la página citada por Riaño, pone de relieve la calidad de las labores de ebanistería de la sacristía de la Cartuja.

${ }^{14}$ En la documentación del Museo V\&A está la nota original de Martín y su traducción. 


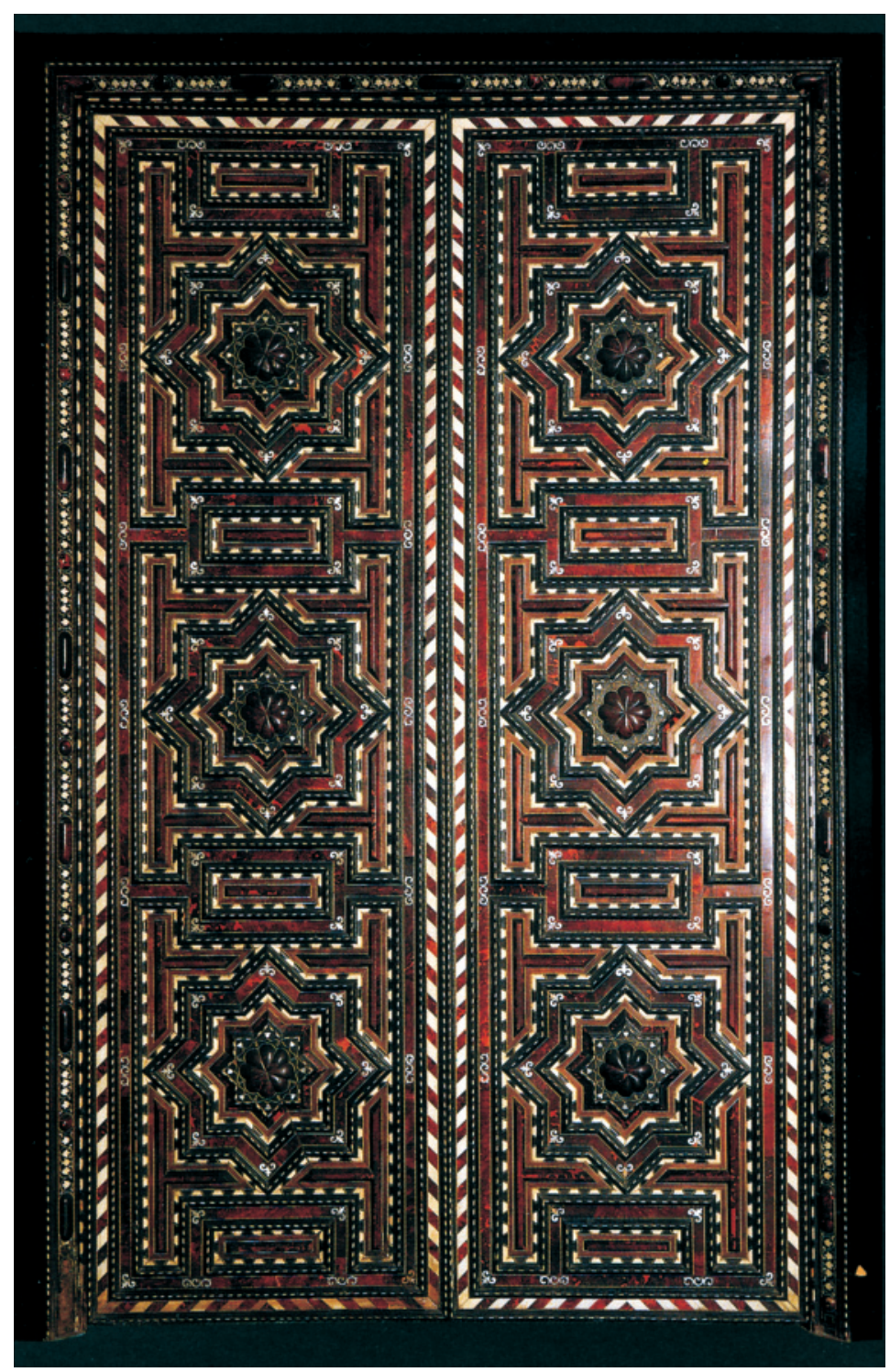

Fig. 4. Puerta de marquetería 1870-80. Museo Franz Mayer. México D.F.

mos, de su compra por coleccionista fundador del museo ${ }^{15}$. Sensiblemente más baja que las originales (fig. 3), carece de la cornisa y pináculos de aquellas. En la sacristía granadina las puertas de los armarios se enrasan mediante una moldura de sección mixtilínea igual a las que forman el marco, en la de Franz Mayer el cordón bicolor de cada hoja se junta en el centro mientras las

15 Reproducida en prácticamente todos los catálogos y libros de la colección mexicana como obra bella y característica de lo hispano, su conservación, protegida por láminas de metacrilato, impide un fácil acceso a la misma. 


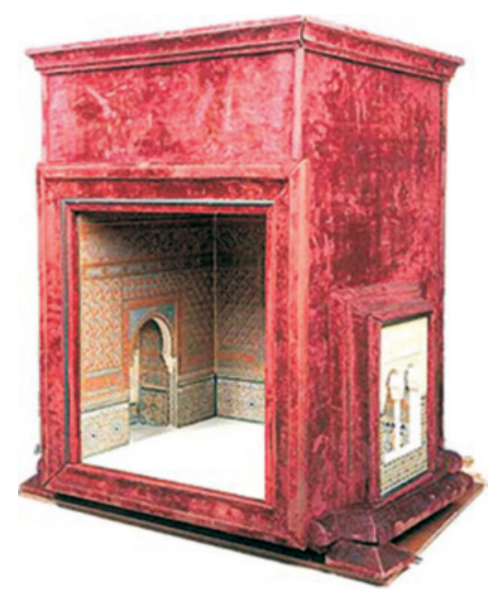

Fig. 5. Modelo de la Torre de la Cautiva. Taller de Contreras 1880.

bisagras quedan insertas en una moldura añadida decorada a su vez con perlas de hueso y óvalos de carey a modo de cabujones.

Del segundo tipo a que se refiere tanto los papeles de Riaño como el párrafo de Gómez Moreno, el mobiliario hecho por Rafael Contreras, era de dos estilos: uno el taburete cubierto de placas plateadas de cobre reproduciendo la ornamentación de estucos de la Alhambra "del estilo de algunos pequeños que ya tiene el Kensington Museum reproducidos mediante la galvanoplastia". Para Riaño la abundancia del metal producía un efecto demasiado rico y monótono debido al recubrimiento exclusivo de la plata, opinando que podría ser útil para objetos pequeños ${ }^{16}$, pese a lo que propuso comprar el mobiliario de Contreras ya en $1875^{17}$.

Como indicó Tonia Requejo en su exhaustivo análisis sobre la Alhambra en el Museo Victoria \& Albert, la incorporación de la clase media inglesa a los gustos de la aristocracia fomentó el comercio de las reproducciones. Los talleres granadinos contribuyeron, enormemente por su parte, a distribuir la imagen de la Alhambra ${ }^{18}$. Los establecimientos más visitados por los ingleses, una vez vistas las grandes reproducciones en el museo londinense, fueron los de Rafael Contreras, entre cuyas realizaciones se contaban los modelos en yeso a pequeña escala de diversas partes del monumento, con destino meramente decorativo (fig. 5) ${ }^{19}$, así como piezas de mobiliario que contribuyeron a difundir el gusto por objetos cotidianos "de gusto oriental", los cuales mediante las técnicas empleadas de vaciado y galvanoplastia con color para imitar la plata oxidada, producían una excelente sensación aparente de riqueza.

Precisamente de esa actividad ebanística de la familia Contreras pueden ser muestra un ejemplo recientemente aparecido en el comercio de arte bonaerense: un armario-vitrina con mocárabes al frente que reproduce la Puerta del Vino, utilizando metal plateado y cristal y cuyos costados van además chapeados en marquetería de madera de dos tonos formando una lacería en la que se insertan las placas metálicas, reproducidas a partir de los vaciados de las yeserías (figs. 6-8). En el reverso de una de estas aparece la fecha de realización: 1891. Una placa de metal la identifica como procedente de "CONTRERAS E HIJO. Alhambra. GRANADA" (fig. 9). Su construcción no demasiado esmerada, pero sobre todo su decoración confirman una vez más las certeras opiniones de don Manuel Gómez Moreno.

\footnotetext{
16 (Sig. J. F. Riaño) Purchase.

17 Trusted, M., op. cit., nota 33.

18 Requejo, Tonia, "La Alhambra en el Museo Victoria \& Albert. Un catálogo de las piezas de la Alhambra y de algunas obras neonazaries”. Cuadernos de Arte e Iconografia I, 1988.

${ }_{19}$ MarquÉs, Sofía, "Mixed Media Objet: large \& fragile structure". Victoria \& Albert. Conservation Journal. Autumn 2004, núm. 48.
} 

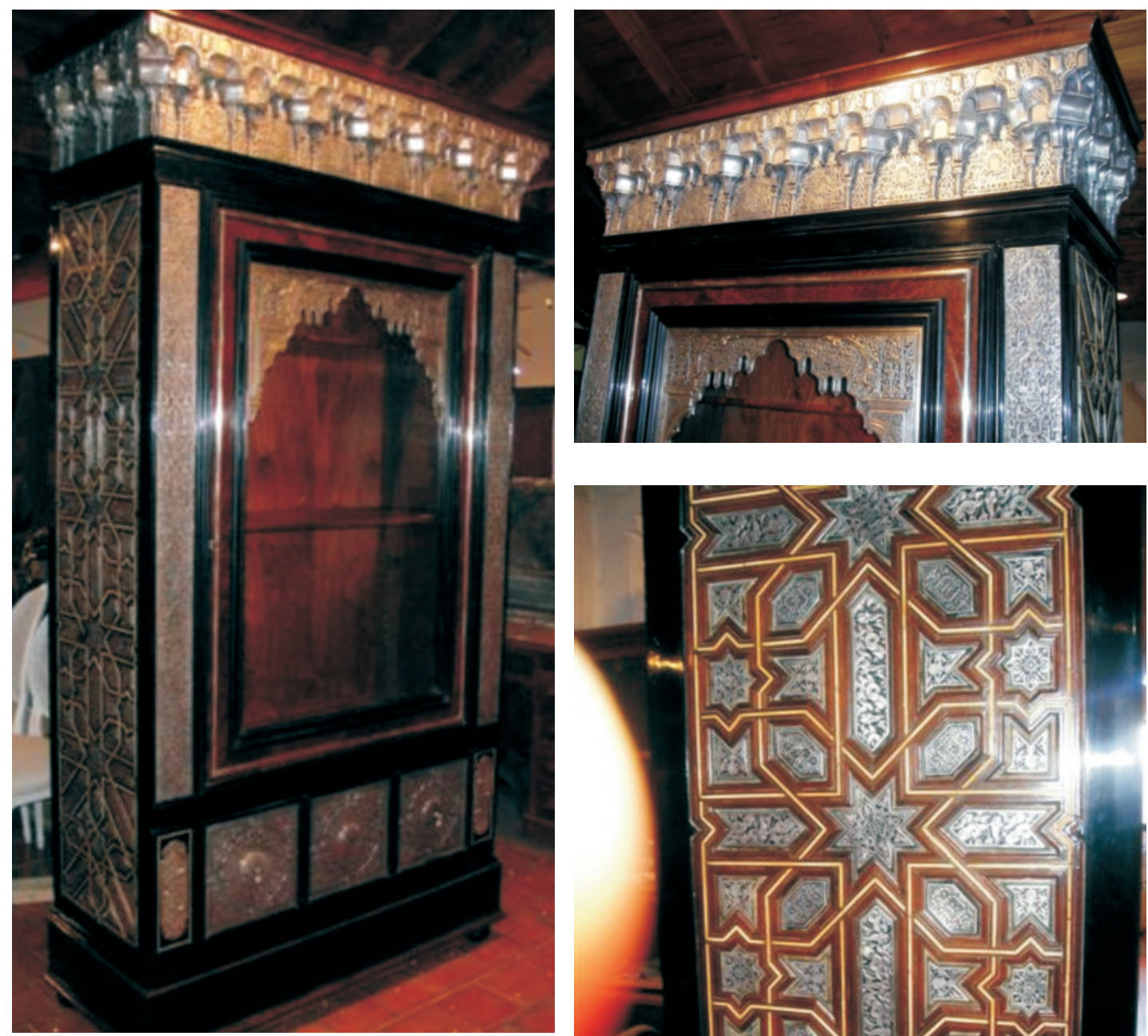

Figs. 6-8. Armario. Taller de Contreras. Granada 1891.

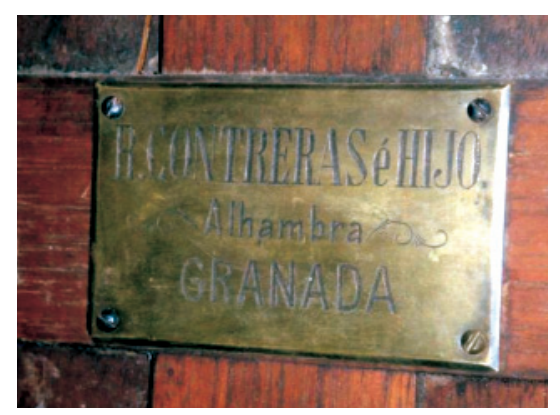

Fig. 9. Placa identificativa del mismo.

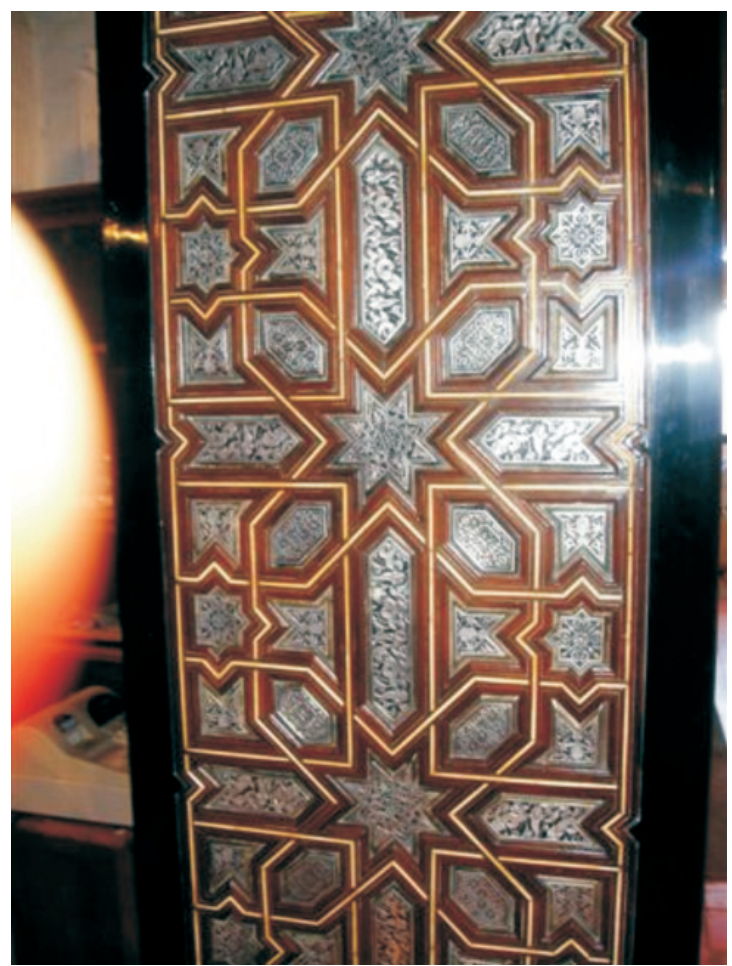

AEA, LXXXII, 328, OCTUBRE-DICIEMBRE 2009, 393-424, ISSN: 0004-0428 